\title{
Mirror Image Modeling of Acetabular Rim Thickness Differences in Patients With Unilateral Femoroacetabular Impingement Syndrome
}

\author{
Andrew J. Riff, M.D., Alexander E. Weber, M.D., Timothy C. Keating, M.D., \\ Benedict U. Nwachukwu, M.D., M.B.A., Edward C. Beck, M.D., M.P.H., \\ Nozomu Inoue, M.D., Ph.D., Laura M. Krivicich, B.S., and Shane J. Nho, M.D., M.S.
}

\begin{abstract}
Purpose: To use mirror imaging to identify the location and magnitude of difference in acetabular rim morphology between the symptomatic and unaffected acetabula in patients with symptomatic unilateral pincer-type or mixed femoroacetabular impingement syndrome (FAIS) using 1-dimensional models created with computed tomography (CT). Methods: CT scans of bilateral hips in 33 patients diagnosed with unilateral pincer-type or mixed FAIS were obtained. Three-dimensional bilateral hip models were constructed, and the unaffected hemipelvis was superimposed onto the symptomatic side to compare acetabular thickness. Protrusion of the symptomatic side was recorded, and rim morphology was divided into clock face quadrants to analyze the location of greatest magnitude of difference between affected and unaffected acetabula. Analysis of the quadrants was performed using analysis of variance with post hoc Bonferroni correction. Results: The study group consisted of more females $(51.6 \%)$ than males, with an average age of $35.72 \pm 7.8$ years and an average body mass index of $24.3 \pm 4.1 \mathrm{~kg} / \mathrm{m}^{2}$. Of the 33 hips included, 14 were isolated pincer-type FAIS and 19 were mixed. The average preoperative symptomatic side lateral center edge angle was $37.5^{\circ} \pm 7.2^{\circ}$ compared with $29^{\circ} \pm 5.1^{\circ}$ on the asymptomatic side $(P=.001)$. The symptomatic acetabular rim was on average $0.43 \pm 0.18 \mathrm{~mm}$ thicker than the corresponding location on the unaffected rim. When the acetabulum was divided into clock face quadrants, the 12 to $3 \mathrm{o}^{\prime}$ clock position showed the greatest difference between symptomatic and unaffected sides $(0.55 \pm 0.18 \mathrm{~mm})$ compared with the 3 to $6 \mathrm{o}^{\prime}$ clock position $(0.4 \pm$ $0.28 \mathrm{~mm} ; P=.006), 6$ to 9 o'clock $(0.34 \pm 0.07 \mathrm{~mm} ; P<.001)$, and 9 to 12 o'clock $(0.38 \pm 0.03 ; P=.001)$. Conclusions: Patients with unilateral, symptomatic pincer-type or mixed FAIS show statistical differences in rim thickness between the affected and unaffected acetabula. Small changes in acetabular rim morphology on the order of $\leq 0.5 \mathrm{~mm}$ may be the difference between symptomatic FAIS and the unaffected hip. Level of Evidence: IV, case series.
\end{abstract}

$\mathbf{O}$ sseous abnormalities of the femoral head-neck junction and acetabular rim leading to the clinically painful hip form the basis of cam-type, pincer-

From the Division of Sports Medicine, Department of Orthopedic Surgery, Rush University Medical Center, Chicago, Illinois, U.S.A.

The authors report the following potential conflicts of interest or sources of funding: S.J.N. reports nonfinancial support from Allosource, Arthrex Inc., Athletico, DJ Orthopaedics, Linvatec, Miomed, Smith $\theta$ Nephew, Stryker; other from American Journal of Orthopedics, American Orthopaedic Society for Sports Medicine, Arthroscopy Association of North America; personal fees from Ossur; personal fees and nonfinancial support from Springer. Full ICMJE author disclosure forms are available for this article online, as supplementary material.

Received October 3, 2017; accepted June 17, 2019.

Address correspondence to Edward C. Beck, M.D., 1611 W Harrison St, Suite 200, Chicago,IL 60612,U.S.A.E-mail: edward.beck@rushortho.com

(C) 2019 by the Arthroscopy Association of North America. Published by Elsevier Inc. This is an open access article under the CC BY-NC-ND license (http://creativecommons.org/licenses/by-nc-nd/4.0/).

2666-061X/171189

https://doi.org/10.1016/j.asmr.2019.06.001 type, and mixed femoroacetabular syndrome (FAIS). ${ }^{1}$ Focal or relative acetabular overcoverage of the acetabulum can lead to pincer-type FAIS, whereas undercoverage of a dysplastic acetabulum may lead to hip instability. ${ }^{2}$ The accuracy of radiographic parameters used to define normal FAIS, pincer-type FAIS, and hip dysplasia have recently been called into question. ${ }^{3-5}$ Computed tomography (CT) and 3-dimensional (3D) imaging may provide a better understanding of pathomorphology and more accurate parameters to define pincer-type FAIS. . $^{6,7}$

Some authors have advocated for rim resection in the presence of pincer-type FAIS for a number of reasons, including directly addressing the osseous abnormality, resecting already damaged cartilage, and protecting the repaired labrum and preserved cartilage from future damage. ${ }^{8}$ However, the magnitude of rim resection must balance between underresection, leading to residual impingement, and overresection, leading to 
iatrogenic hip instability. ${ }^{9-12}$ Templating of rim resection has been investigated with a number of different preoperative and intraoperative techniques, including anterior and lateral center edge angle (LCEA) resection formulas. ${ }^{8,13-19}$ However, in unilaterally symptomatic patients, the best template for restoring normal anatomy and preventing the complications of over- or underresection may be the unaffected hip. As such, the purpose of this study was to use mirror imaging to identify the location and magnitude of difference in acetabular rim morphology between the symptomatic and unaffected acetabula in patients with symptomatic unilateral pincer-type or mixed FAIS using 1D models created with CT. Our hypothesis was that the acetabular rim would be more prominent on the affected side compared with the healthy, unaffected side.

\section{Methods}

After Institutional Review Board approval, data on all patients who underwent hip arthroscopy for the treatment of FAIS by a single, fellowship-trained surgeon were retrospectively collected and analyzed. All patients undergoing primary hip arthroscopy for the treatment of FAIS between January 1, 2012, and December 1, 2012, were screened for inclusion in the study. Inclusion criteria consisted of patients with unilateral clinical history and symptoms consistent with FAIS $^{20}$ with evidence of mixed-type or pincer-type FAIS. Pincer-type FAIS was defined as either an anterior center edge angle (ACEA) or LCEA $>39^{\circ}$, a positive crossover sign, ischial spine sign, or coxa profunda. ${ }^{21}$ Exclusion criteria included patients with a history of previous ipsilateral and contralateral hip surgery, radiographic evidence of contralateral cam lesion or acetabular overcoverage, history of pediatric congenital hip disorders (e.g. slipped capital femoral epiphysis, avascular necrosis, developmental hip dysplasia), and those without preoperative bilateral hip CT scans.

\section{Radiographic Analysis}

All patients had a series of preoperative radiographs. ${ }^{22}$ Each series consisted of a standing anteroposterior pelvis radiograph, an anteroposterior hip radiograph, a false-profile hip radiograph, and a Dunn lateral hip radiograph. ${ }^{23}$ The alpha angle of both symptomatic and unaffected hips was measured on the anteroposterior, false-profile, and Dunn lateral hip views. ${ }^{24-26}$ The LCEA was measured on the anteroposterior hip radiograph. ${ }^{23,25}$

\section{D Reconstruction of the Symptomatic and Unaffected Hips}

All preoperative bilateral hip CT scans were performed using a protocol previously described. ${ }^{27}$ The CT images of both hips from patients meeting the inclusion criteria were retrospectively obtained in DICOM format and segmented using 3D reconstruction software (Mimics; Materialise) (Fig 1). The 3D CT models were further converted to point-cloud models using a custom-written program (Microsoft Visual $\mathrm{C}++$, Microsoft Corp.) as previously described. ${ }^{28}$ The pointcloud data of the unaffected hemipelvis was mirrored to the affected hemipelvis (Fig 2). Orientation of the rim model was calculated based on the fovea and transverse acetabular ligament position. Clock face quadrants were assigned with the femoral head center as the center of the clock face and the projected midpoint as 6 o'clock. $^{\prime}$

Points on the greater sciatic notch of the right hemipelvis model and the mirrored left hemipelvis model were merged using a validated 3D-3D registration method (accuracy $0.1 \mathrm{~mm}$ in translation, $0.2^{\circ}$ in rotation). The rim models were also transformed using the transformation matrix calculated to merge the hemipelvis models. The closest point in the hemipelvis in the unaffected side from a point in the rim model in the symptomatic side was searched. A vector was created from the point in the rim model to the closest point in the hemipelvis. An angle $(\theta)$ between the vector and the normal vector of the rim plane was calculated by dot product of the vectors, and bony protrusion $\left(\theta<90^{\circ}\right)$ and indentation $\left(\theta>90^{\circ}\right)$ was determined in reference to the unaffected hemipelvis. The magnitude of protrusion or indentation was determined by direction cosine of the vector (protrusion, positive sign; indentation, negative sign). The procedure was repeated for all points in the rim model. The points in the rim model were grouped by the angles (time) into $3^{\circ}$ intervals, and the magnitude of the bony protrusion or indentation was averaged within $3^{\circ}$ intervals. The averaged intervals were color mapped for ease of visual comprehension (Fig 3).

\section{Statistical Analysis}

Symptomatic and unaffected hip radiographic parameters were compared using independent $t$ tests. Rim morphology was broken into quadrants using the clock face method to analyze the location of greatest magnitude of difference between affected and unaffected acetabula. Rim morphology differences between the quadrants were compared using analysis of variance with post hoc Bonferroni correction. Statistical difference was set at $P<.05$ for all testing. All statistical tests were performed using SPSS software (version 24.0, IBM Corp.). All averages are expressed a mean \pm standard deviation unless otherwise stated.

\section{Results}

A total of 33 patients were included in the final analysis. The patient demographics are summarized in Table 1 . The study group consisted of more females $(51.6 \%)$ than males, with an average age of $35.72 \pm 7.8$ years and an 
Fig 1. Bilateral 1-dimensional computed tomography reconstructions of the acetabula of a patient with unilateral symptomatic FAI. (A) Representative symptomatic right hemipelvis with red arrow denoting the anterosuperior bony prominence. (B) Representative unaffected left hemipelvis with the absence of anterosuperior bony prominence.

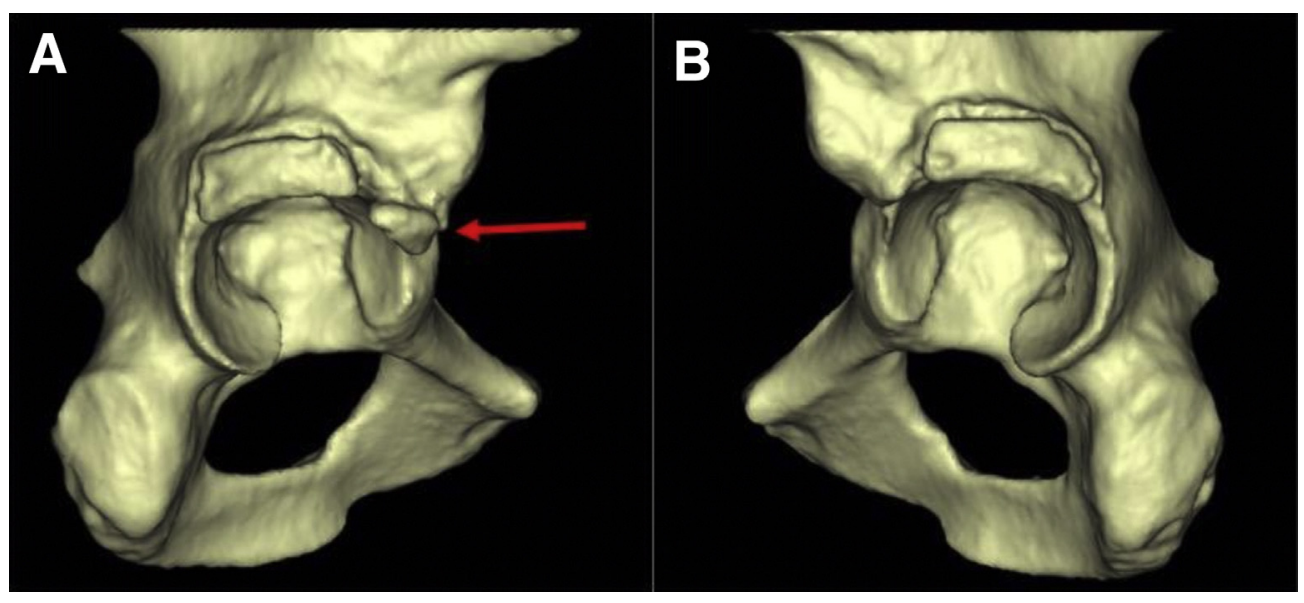

average body mass index of $24.3 \pm 4.1 \mathrm{~kg} / \mathrm{m}^{2}$. There were 14 cases of isolated pincer-type FAIS and 19 cases of mixed FAIS. The symptomatic hip was the left side in 17 patients and right side in 16 cases.

\section{Radiographic Analysis}

The average preoperative symptomatic side LCEA was $37.5^{\circ} \pm 7.2^{\circ}$ compared with $29^{\circ} \pm 5.1^{\circ}$ on the unaffected side $(P=.001)$. The average preoperative symptomatic ACEA was $39.2^{\circ} \pm 6.5^{\circ}$. The average preoperative alpha angle on the symptomatic side was $61.1^{\circ} \pm 12.7^{\circ}$. The postoperative LCEA of the symptomatic side significantly decreased at final follow-up to $32.5^{\circ} \pm 6.0^{\circ}(P<.001)$, as did the average alpha angle at final follow-up, to $39.6^{\circ} \pm 4.9^{\circ}(P<.001)$.

\section{Comparison of Acetabular Thickness Between Symptomatic and Unaffected Acetabular Rims}

When the preoperative symptomatic acetabular rim was examined in its entirety, each $3^{\circ}$ interval was on average $0.43 \pm 0.18 \mathrm{~mm}$ thicker than the corresponding interval location on the unaffected rim. When the acetabular clock face was broken up into quadrants (reflecting the 12 to 3,3 to 6,6 to 9 , and 9 to $12 \mathrm{o}^{\prime}$ clock positions), the 12 to 3 o'clock position showed the greatest difference between symptomatic and unaffected sides. Post hoc analysis with Bonferroni correction showed that the 12 to 3 o'clock quadrant showed significantly greater difference between symptomatic and unaffected sides $(0.55 \pm 0.18 \mathrm{~mm})$ compared with the 3 to 6 o'clock position $(0.4 \pm 0.28 \mathrm{~mm} ; P=.006)$, the 6 to $9 \mathrm{o}^{\prime}$ clock position $(0.34 \pm 0.07 \mathrm{~mm} ; P<.001)$, and the 9 to $12 \mathrm{o}^{\prime}$ clock position $(0.38 \pm 0.03 ; P<.001)$ (Table 2).

\section{Discussion}

The main finding of the present study is that the most significant area of the acetabular rim thickening is in the 12 to 3 o'clock position, which has been previously shown to be the most common area for symptomatic FAIS based on mechanical loading in this region. The present study suggests that small differences in rim thickness, on the order of less than a millimeter, may be the difference between a symptomatic FAIS hip and an unaffected hip. Furthermore, mirror imaging analysis serves as a method for identifying the statistical differences in rim thickness between the symptomatic hip

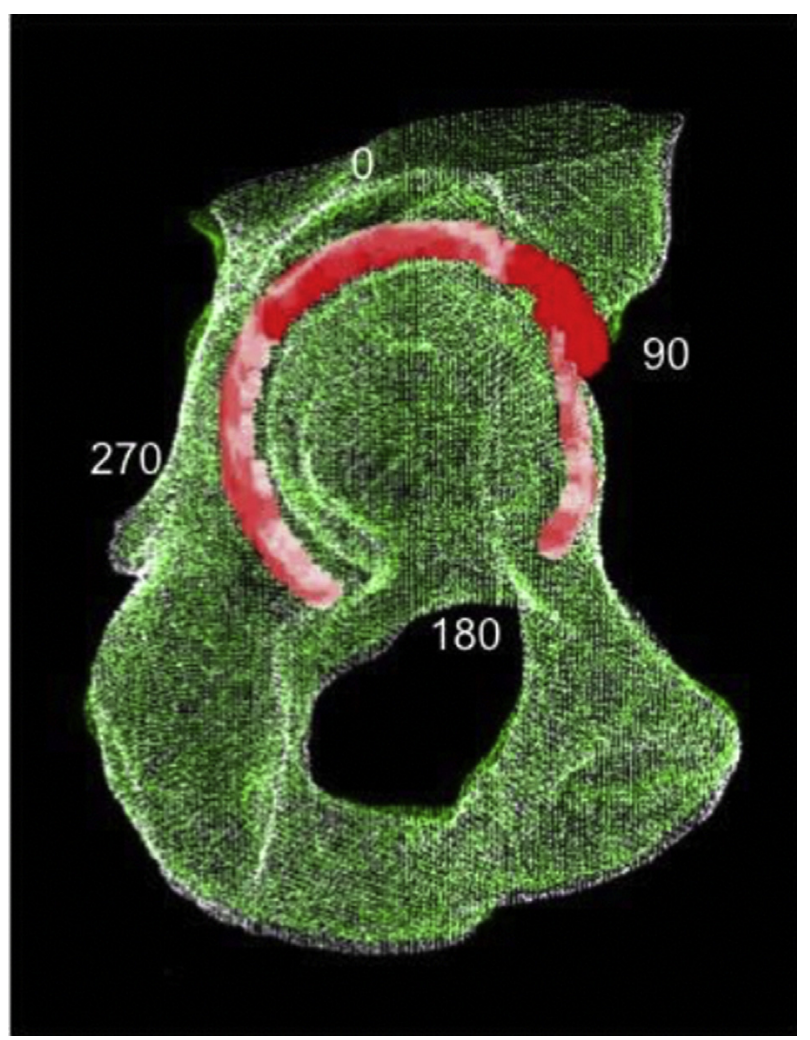

Fig 2. Symptomatic (green) and unaffected (white) 1dimensional computed tomography reconstructions of the same patient from Fig 1 mapped onto each other using the clock face as orientation. Areas of protrusion of the symptomatic hip are marked in red. 


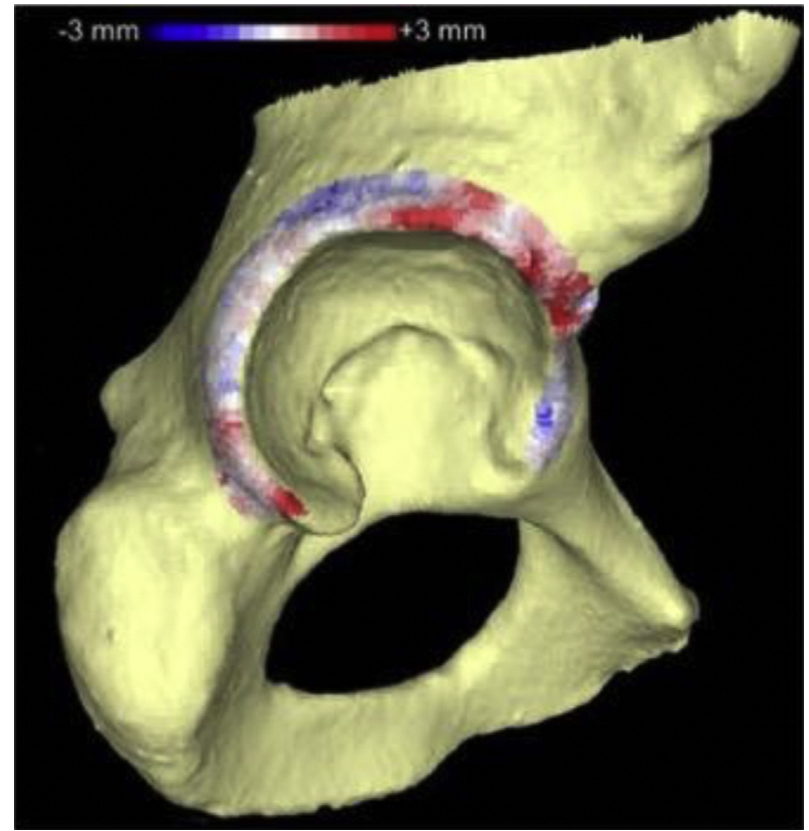

Fig 3. The final color map of the overlaid unaffected acetabulum onto the affected acetabulum (from the same patient as Figs 1 and 2). The rim thickness comparisons are color mapped. Red indicates a protrusion of the affected, symptomatic acetabulum compared with the unaffected side.

with pincer lesions in a patient with unilateral FAIS and the unaffected hip.

Symptomatic FAIS is characteristically painful with hip flexion, adduction, and internal rotation. ${ }^{29}$ The explanation is that this position imparts mechanical load on the impinging femoral head/neck and acetabulum. ${ }^{30}$ This is also the explanation for the characteristic bony abnormalities in cam-type FAIS (anterolateral femoral neck) and pincer-type FAIS (anterosuperior acetabulum). The nature of bone to increase apposition in response to mechanical load ${ }^{19,31}$ is likely a critical factor in the development and progression of FAIS and pincer hypertrophy ${ }^{.32-35}$ Prior FAIS studies have correlated alpha angle or severity of disease with training intensity, which suggests a mechanobiological etiology to FAI. ${ }^{33,34,36,37}$ Siebenrock et al. ${ }^{34}$ performed

Table 1. Patient Demographics

\begin{tabular}{lc}
\hline Age $(\mathrm{yr})$ & $35.7 \pm 7.8$ \\
Body mass index $\left(\mathrm{kg} / \mathrm{m}^{2}\right)$ & $24.3 \pm 4.1$ \\
Sex & $16(48.4)$ \\
$\quad$ Male & $17(51.6)$ \\
$\quad$ Female & \\
Laterality & $17(51.6)$ \\
$\quad$ Left & $16(48.4)$ \\
$\quad$ Right & \\
FAIS type & $14(42.4)$ \\
$\quad$ Pincer only & $19(57.6)$ \\
$\quad$ Mixed & \\
\hline NOTE. Data are mean \pm standard deviation or $\mathrm{n}(\%)$. & \\
FAIS, femoroacetabular syndrome. &
\end{tabular}

Table 2. Comparison of Acetabular Rim Thickness Differences by Clock Face Position

\begin{tabular}{lcr}
\hline Clock Position & Rim Thickness Difference & $P$ Value \\
\hline 12 to 3 & $0.55 \pm 0.18$ & \\
3 to 6 & $0.4 \pm 0.28$ & .006 \\
6 to 9 & $0.34 \pm 0.07$ & $<.001$ \\
9 to 12 & $0.38 \pm 0.03$ & .001 \\
Total Average & $0.43 \pm 0.18$ & .002 \\
\hline
\end{tabular}

a magnetic resonance imaging analysis of 37 adolescent male basketball players compared with 38 age-matched controls and found that the athletes had a 10-fold increase in the likelihood of having an alpha angle $>55^{\circ}$. Furthermore, Haider et al. ${ }^{32}$ have recently investigated the biologic response to mechanical loading by comparing the biomechanical properties of cam deformity subchondral bone to the subchondral bone of healthy controls. They found increased stiffness in the subchondral bone of cam deformity subjects. ${ }^{32}$

In the present cohort of unilateral pincer-type or mixed FAIS patients, the symptomatic acetabular rim was found to be significantly thicker than the unaffected, unaffected acetabular rim. Additionally, the largest magnitude of rim thickness difference between unaffected and symptomatic hips was found to occur in the anterosuperior quadrant (12 to $3 \mathrm{o}^{\prime}$ clock), where the mechanical loading is at its highest. Although we are unable to ascertain causality, the increase in rim thickness on the affected side suggests further prospective studies on the etiology of FAIS and on quantifying femoral morphology between the affected and unaffected sides with similar methodology. Therefore, rather than applying universal radiographic parameters to all patients, when possible it may be best to use the unaffected hip morphology as a template for surgical correction of the symptomatic side.

The results of the current study are also important in regard to the current debate over what constitutes normal acetabular morphology. There is currently controversy about normal and abnormal acetabular rim morphology and what radiographic or advanced imaging parameter or parameters are used to measure "normal." 7,16 Radiographic parameters alone have been shown to be poor predictors of pincer-type FAI. ${ }^{3-5}$ CTbased studies and 3D studies have attempted to qualify and quantify normal and abnormal parameters for acetabular volume and morphology. ${ }^{6,7}$ However, we submit that in unilateral FAI, the unaffected hip may serve as the most reliable marker of "normal" for that particular patient. This point is further illustrated by the many studies that have identified radiographically positive FAIS in asymptomatic volunteers. ${ }^{38-40}$

Surgical correction of pincer-type FAIS must balance between underresection, resulting in potential continued FAIS symptoms, and overresection, resulting 
in iatrogenic instability. Prior studies have implemented formulas based on ACEAs or LCEAs. ${ }^{8,14,16}$ A prior study by Kling et al. ${ }^{16}$ showed that small rim resections in a cadaver model caused large changes in ACEAs or LCEAs. In their study, a cadaveric rim resection of $5 \mathrm{~mm}$ caused 2 of 12 specimens to become dysplastic as measured by ACEAs and LCEAs. A resection of $7.5 \mathrm{~mm}$ caused $50 \%$ of the specimens to become unstable and require an externally applied force to maintain hip joint reduction. ${ }^{16}$ Philippon et al. ${ }^{8}$ found that 1 and $2 \mathrm{~mm}$ of rim resection correlated with a change in LCEA of $2.4^{\circ}$ and $3.1^{\circ}$, respectively. In the current study, we found that the average difference in preoperative LCEA between symptomatic and unaffected acetabula was 8.5 , whereas the difference in anterosuperior rim thickness was $0.5 \mathrm{~mm}$. This highlights previous findings by Hanson et al. ${ }^{41}$ that LCEA may be an inconsistent way of measuring acetabular overcoverage.

Although the findings of the current study suggest that smaller changes in rim thickness are potentially the difference between a symptomatic and an unaffected hip, there may be additional factors such as the magnitude of cam-type morphology and the role of soft tissue interposition that affect the level of symptoms. Future work should include an analysis of side-to-side differences preoperatively and postoperatively to assess the ability of acetabular rim recession to restore rim thickness to a normal or near-normal state. In addition, future prospective studies should correlate rim differences and rim resection to patient outcomes.

\section{Limitations}

There are a number of limitations in the current study that must be addressed. First, we used LCEA identify patients with pincer deformity, which has been shown to have limitations when measuring acetabular coverage.$^{41}$ It is possible that some hips with borderline overcoverage were mislabeled as having pincer deformity, resulting in underestimation of differences in thickness. We also used crossover sign, center edge angle, and posterior wall sign to identify patients with pincer deformity. It is possible that these patients have more subtle differences in acetabular thickness between the affected and unaffected hips. Second, due to the limitations of requiring bilateral hip CTs and earlier protocols obtaining only symptomatic hip CTs, the current study had a limited sample size. Furthermore, an a priori sample size analysis was not performed since, to our knowledge, there is no study in the current literature comparing acetabular rim thickness of the symptomatic and unaffected side that could be used as an effect size for the power analysis. However, based on a post hoc analysis using the differences in LCEA for effect size, the observed power is 0.966 . In addition, our results show statistical differences, but the magnitude of these differences is small. The clinical significance of our results requires additional investigation, clarification, or corroboration. Finally, the side-to-side comparisons are made for preoperative patients.

\section{Conclusions}

Patients with unilateral, symptomatic pincer-type FAIS, or mixed FAIS show statistical differences in rim thickness between the affected and unaffected acetabula. Small changes in acetabular rim morphology, on the order of $\leq 0.5 \mathrm{~mm}$, may be the difference between symptomatic FAIS and the unaffected hip.

\section{References}

1. Ganz R, Parvizi J, Beck M, Leunig M, Notzli H, Siebenrock KA. Femoroacetabular impingement: a cause for osteoarthritis of the hip. Clin Orthop Relat Res 2003: 112-120.

2. Bedi A, Dolan M, Leunig M, Kelly BT. Static and dynamic mechanical causes of hip pain. Arthroscopy 2011;27: 235-251.

3. Clohisy JC, Carlisle JC, Trousdale R, et al. Radiographic evaluation of the hip has limited reliability. Clin Orthop Relat Res 2009;467:666-675.

4. Siebenrock KA, Kalbermatten DF, Ganz R. Effect of pelvic tilt on acetabular retroversion: A study of pelves from cadavers. Clin Orthop Relat Res 2003:241-248.

5. Zaltz I, Kelly BT, Hetsroni I, Bedi A. The crossover sign overestimates acetabular retroversion. Clin Orthop Relat Res 2013;471:2463-2470.

6. Buller LT, Rosneck J, Monaco FM, Butler R, Smith T, Barsoum WK. Relationship between proximal femoral and acetabular alignment in normal hip joints using 3dimensional computed tomography. Am J Sports Med 2012;40:367-375.

7. Larson CM, Moreau-Gaudry A, Kelly BT, et al. Are normal hips being labeled as pathologic? A CT-based method for defining normal acetabular coverage. Clin Orthop Relat Res 2015;473:1247-1254.

8. Philippon MJ, Wolff AB, Briggs KK, Zehms CT, Kuppersmith DA. Acetabular rim reduction for the treatment of femoroacetabular impingement correlates with preoperative and postoperative center-edge angle. Arthroscopy 2010;26:757-761.

9. Benali Y, Katthagen BD. Hip subluxation as a complication of arthroscopic debridement. Arthroscopy 2009;25:405-407.

10. Bogunovic L, Gottlieb M, Pashos G, Baca G, Clohisy JC. Why do hip arthroscopy procedures fail? Clin Orthop Relat Res 2013;471:2523-2529.

11. Matsuda DK. Acute iatrogenic dislocation following hip impingement arthroscopic surgery. Arthroscopy 2009;25: 400-404.

12. Ross JR, Larson CM, Adeoye O, Kelly BT, Bedi A. Residual deformity is the most common reason for revision hip arthroscopy: a three-dimensional CT study. Clin Orthop Relat Res 2015;473:1388-1395.

13. Chosa E, Tajima N. Anterior acetabular head index of the hip on false-profile views. New index of anterior acetabular cover. J Bone Joint Surg Br 2003;85:826-829. 
14. Colvin AC, Koehler SM, Bird J. Can the change in centeredge angle during pincer trimming be reliably predicted? Clin Orthop Relat Res 2011;469:1071-1074.

15. Gross CE, Salata MJ, Manno K, et al. New radiographic parameters to describe anterior acetabular rim trimming during hip arthroscopy. Arthroscopy 2012;28:1404-1409.

16. Kling S, Karns MR, Gebhart J, et al. The effect of acetabular rim recession on anterior acetabular coverage: A cadaveric study using the false-profile radiograph. Am J Sports Med 2015;43:957-964.

17. Larson CM, Wulf CA. Intraoperative fluoroscopy for evaluation of bony resection during arthroscopic management of femoroacetabular impingement in the supine position. Arthroscopy 2009;25:1183-1192.

18. Matsuda DK. Fluoroscopic templating technique for precision arthroscopic rim trimming. Arthroscopy 2009;25: 1175-1182.

19. Mofidi A, Shields JS, Tan JS, Poehling GG, Stubbs AJ. Use of intraoperative computed tomography scanning in determining the magnitude of arthroscopic osteochondroplasty. Arthroscopy 201 1;27:1005-1013.

20. Griffin DR, Dickenson EJ, O'Donnell J, et al. The Warwick Agreement on femoroacetabular impingement syndrome (FAI syndrome): An international consensus statement. Br J Sports Med 2016;50:1169-1176.

21. Rhee C, Le Francois T, Byrd JWT, Glazebrook M, Wong I. Radiographic diagnosis of pincer-type femoroacetabular impingement: A systematic review. Orthop J Sports Med 2017; 5:2325967117708307.

22. Weber AE, Jacobson JA, Bedi A. A review of imaging modalities for the hip. Curr Rev Musculoskelet Med 2013;6: 226-234.

23. Clohisy JC, Carlisle JC, Beaule PE, et al. A systematic approach to the plain radiographic evaluation of the young adult hip. J Bone Joint Surg Am 2008;90:47-66 (suppl 4).

24. Notzli HP, Wyss TF, Stoecklin CH, Schmid MR, Treiber K, Hodler J. The contour of the femoral head-neck junction as a predictor for the risk of anterior impingement. $J$ Bone Joint Surg Br 2002;84:556-560.

25. Krych AJ, Thompson M, Knutson Z, Scoon J, Coleman SH. Arthroscopic labral repair versus selective labral debridement in female patients with femoroacetabular impingement: A prospective randomized study. Arthroscopy 2013;29:46-53.

26. Tonnis D, Heinecke A, Nienhaus R, Thiele J. [Predetermination of arthrosis, pain and limitation of movement in congenital hip dysplasia]. Z Orthop Ihre Grenzgeb 1979;1 17: 808-815 [in German].

27. Krishnamoorthy VP, Kunze KN, Beck EC, et al. Radiographic prevalence of symphysis pubis abnormalities and clinical outcomes in patients with femoroacetabular impingement syndrome. Am J Sports Med 2019: 363546519837203.
28. Yanke AB, Khair MM, Stanley R, et al. Sex Differences in patients with CAM deformities with femoroacetabular impingement: 3-dimensional computed tomographic quantification. Arthroscopy 2015;31:2301-2306.

29. Amanatullah DF, Antkowiak T, Pillay K, et al. Femoroacetabular impingement: Current concepts in diagnosis and treatment. Orthopedics 2015;38:185-199.

30. Zebala LP, Schoenecker PL, Clohisy JC. Anterior femoroacetabular impingement: A diverse disease with evolving treatment options. Iowa Orthop J 2007;27:71-81.

31. Campoli G, Weinans H, van der Helm F, Zadpoor AA. Subject-specific modeling of the scapula bone tissue adaptation. J Biomech 2013;46:2434-2441.

32. Haider I, Speirs A, Alnabelseya A, Beaule PE, Frei H. Femoral subchondral bone properties of patients with cam-type femoroacetabular impingement. Osteoarthritis Cartilage 2016;24:1000-1006.

33. Siebenrock KA, Behning A, Mamisch TC, Schwab JM. Growth plate alteration precedes cam-type deformity in elite basketball players. Clin Orthop Relat Res 2013;471: 1084-1091.

34. Siebenrock KA, Ferner F, Noble PC, Santore RF, Werlen S, Mamisch TC. The cam-type deformity of the proximal femur arises in childhood in response to vigorous sporting activity. Clin Orthop Relat Res 2011;469: 3229-3240.

35. Speirs AD, Beaule PE, Rakhra KS, Schweitzer ME, Frei H. Bone density is higher in cam-type femoroacetabular impingement deformities compared with normal subchondral bone. Osteoarthritis Cartilage 2013;21:1068-1073.

36. Lahner M, Walter PA, von Schulze Pellengahr C, Hagen M, von Engelhardt LV, Lukas C. Comparative study of the femoroacetabular impingement (FAI) prevalence in male semiprofessional and amateur soccer players. Arch Orthop Trauma Surg 2014;134:1135-1141.

37. Tak I, Weir A, Langhout R, et al. The relationship between the frequency of football practice during skeletal growth and the presence of a cam deformity in adult elite football players. Br J Sports Med 2015:49:630-634.

38. Gerhardt MB, Romero AA, Silvers HJ, Harris DJ, Watanabe D, Mandelbaum BR. The prevalence of radiographic hip abnormalities in elite soccer players. Am J Sports Med 2012;40:584-588.

39. Kang RW, Park C, Ranawat A. Computer tomography scan of the hip and pelvis. Hip Arthrosc Hip Joint Pres Surg 2015:53-63.

40. Larson CM, Sikka RS, Sardelli MC, et al. Increasing alpha angle is predictive of athletic-related "hip" and "groin" pain in collegiate National Football League prospects. Arthroscopy 2013;29:405-410.

41. Hanson JA, Kapron AL, Swenson KM, Maak TG, Peters CL, Aoki SK. Discrepancies in measuring acetabular coverage: Revisiting the anterior and lateral center edge angles. J Hip Preserv Surg 2015;2:280-286. 